\title{
Classificação de imagens multiespectrais LANDSAT TM e feições de textura: mapeamento da cobertura da terra
}

\author{
Ruth Emília Nogueira Lock \\ Flávio Felipe KIRChNER
}

\begin{abstract}
RESUMO
Este trabalho mostra os resultados iniciais de uma pesquisa sobre classificação de imagens multiespectrais considerando feições de textura, aplicada ao mapeamento da cobertura da terra, com ênfase na separação das classes de cobertura vegetal. Para tanto foi efetuado um levantamento bibliográfico e estudo sobre o assunto, que está resumido na parte inicial. Na seqüência relata-se a parte prática, onde foi feita a classificação multiespectral da imagem LANDSAT-5 TM da Ilha de São Francisco do Sul-SC, utilizando o algoritmo de classificação Máxima verossimilhança. Para testar as potencialidades das feições de textura foram efetuadas quatro classificações distintas para obter as mesmas informações agrupadas em dez classes. Na primeira etapa foi efetuada somente a classificação multiespectral, nas outras foram consideradas feições de textura e classificação espectral.
\end{abstract}

Palavras chave: Sensoriamento Remoto, análise textural, mapeamento da cobertura da terra.

\section{ABSTRACT \\ Classification of LANDSAT TM's Multiespectral Images and Texture} Features: land cover mapping. This paper shows the initial results of a research regarding multiespectral image classification using texture analysis for land cover maping. A bibliographic review was conducted wich is disposed in the first part of this work. Following this, a classification of the LANDSAT TM image of São Francisco island, SC, was performed using the Maximum Likelihood Method. To test the texture analysis potentialities, four distinct classifications were performed to obtain the same informations grouped into ten classes. In the first one only a multiespectral classification was performed, and in the other three the texture analysis was considered.

Key words: Remote Sensing, texture analysis, land cover maping. 


\section{INTRODUÇÃO}

Para extrair informações de imagens de sensores remotos o intérprete considera, na interpretação visual, características como o contexto, formas, bordas, variações tonais ou cores, e textura.

$\mathrm{Na}$ interpretação digital, a maioria das técnicas-padrão de classificação disponíveis apresentam algoritmos de classificação baseados somente no uso da informação espectral, ou seja, na intensidade de cinza ou características tonais, deixando de lado as outras características consideradas na interpretação visual. Mas, pesquisas vem sendo efetuadas para incluir estas outras características para a extração automática de informações de imagens.

A textura pode ser pensada em termos suas características como um subpadrão ou primitiva, e por uma regra de localização que define sua distribuição espacial; ou também se poderia pensar a textura como um fenômeno organizado composto de padrões que obedecem alguma regra estatística (HARALICK \& SHAPIRO, 1992 e VISA, 1990).

Para SCHOWENGERDT (1983), não existe uma caracterização definitiva de textura, mas, todas as definições numéricas são descritas para rugosidade e contraste dos detalhes da imagem. Ele define textura como uma propriedade local de uma imagem, i.e., uma medida da intensidade de cinza entre os pixels e sua vizinhança.

No processamento digital de imagens de sensoriamento remoto, as feições texturais contém informações sobre a distribuição espacial das variações tonais dentro de uma banda, e as feições espectrais descrevem a variação tonal das várias bandas de uma imagem. Enquanto a classificação multiespectral é um processo de agrupamento de pixels de valores de intensidade espectral igual ou muito próximos, na análise textural, ao contrário, a diferença das feições tonais é que irão caracterizá-la, portanto ela é expressa pela diferença entre as intensidades dos pixels vizinhos, e será sempre fundamentada em uma operação de área ou vizinhança(CRÓSTA, 1992).

A pesquisa que é apresentada neste artigo teve como principal objetivo verificar a contribuição da análise textural à classificação espectral de imagens multiespectrais do LANDSAT-5 TM, para a discriminação das classes de cobertura da terra, com ênfase na separação das classes de cobertura vegetal.

\section{FUNDAMENTAÇÃO TEÓRICA}

\section{APLICAÇÕES DA ANÁLISE TEXTURAL}

Entre as aplicações que vêm utilizando a análise textural de dados espectrais, PEDDLE \& FRANKLIN (1991) citam: análise da Terra; mapeamento florestal; monitoramento ambiental e estudos ecológicos.

No mapeamento da cobertura da terra utilizando a imagem multiespectral SPOT HRV, FRANKLIN \& PEDDLE (1990) empregaram matrizes de coocorrência espacial e medidas estatísticas da textura como a entropia e o momento diferencial inverso. Os autores relatam que houve um aumento significativo na 
acuracidade da classificação espectral, com melhoria em $10 \%$ na distinção de rochas expostas e $40 \%$ para a floresta e solos com elevado teor de matéria orgânica. A acuracidade média obtida para a classificação foi de $51 \%$ quando utilizaram somente a classificação espectral, e 86,37\% quando somaram à classificação espectral a entropia medida na banda 2 e o momento diferencial inverso na banda 3. Os autores observaram que as classes homogêneas na superfície foram caracterizadas adequadamente com a classificação espectral sozinha, mas, as classes de padrões mistos de vegetação ou de relevo acidentado, foram caracterizadas mais acuradamente quando foi utilizada a análise textural junto à espectral. Dentro de diferentes tipos de florestas a contribuição da análise textural também foi diferenciada, mostrando-se mais eficaz na caracterização da floresta decídua (98\%) e de coníferas adultas (72\%), que nas áreas de capoeira $(58 \%)$.

PEDDLE \& FRANKLIN (1991) avaliaram a melhoria da acuracidade na classificação de dados da imagem Spot Multiespectral (MLA) e imagens de radar de abertura sintética (SAR), utilizando análise da textura e integrados aos dados de geomorfometria e topografia. Concluíram que em todos os casos a acuracidade da classificação aumentou, como por exemplo, para a imagem SAR sozinha: $36 \%$; SAR com textura: 47\%; Imagem MLA sozinha 73\%; MLA com textura: $88 \%$; MLA com geomorfometria e textura: $98 \%$. Os autores confirmam que matrizes de co-ocorrência contém informações texturais importantes que aumentam a discriminação de classes com heterogeneidade interna e padrões estruturais /geomorfométricos.

Para discriminar campos de cultivo, divididos em 5 classes: trigo, milho, soja, alfafa, e floresta. TREITZ, BARBER \& HOWARTH (s.d), utilizaram texturas estatísticas (homogeneidade e entropia) derivadas de funções de densidade de probabilidade de matrizes de co-ocorrência espacial, nas imagens de radar de abertura sintética - SAR.. Os autores consideraram que uma janela de 7x7 pixels melhorava a discriminação entre os cultivos uniformes (de textura suave, semelhantes), particularmente com emprego da entropia. Concluíram que o trigo foi a classe mais facilmente separável das outras, enquanto a alfafa e o milho não conseguiram ser separadas utilizando as medidas texturais.

\section{MEDIDA DE TEXTURA}

Segundo SCHOWENGERDT (1983), a textura pode ser medida por quantidades estatísticas simples, como a variância do nível de cinza local. BARBER \& LEDREW (1991) comentam que existem várias abordagens para medidas de textura, incluindo: estatística, estrutura, valores estocásticos, e análise no domínio das freqüências, as quais são descritas a seguir:

a) As abordagens estatísticas fazem uso da função de probabilidade da densidade de nível de cinza (pdf), que é computada, normalmente, como a probabilidade condicional de articulação de pares de pixel (nível de cinza), num determinado local da imagem. Como exemplos de aproximações estatísticas para a análise da textura pode-se citar: a matriz de co-ocorrência do nível de cinza (GLCM), a 
contagem dos pixels (nível de cinza), e a matriz dependente do nível de cinza vizinho.

b) Abordagens estruturais explorando a noção de textura primitiva: HARALICK \& SHAPIRO (1992), consideram um conjunto de pixels caracterizados pelos seus atributos, onde o pixel com o seu atributo nível de cinza é a mais simples forma de textura primitiva, e a mais complexa primitiva é um conjunto conectado de pixels homogêneos em seu valor.

c) Abordagens estocásticas: assumem que campos de textura podem ser estimados probabilisticamente baseados num modelo de estatística particular, como o de campos aleatórios multidimensionais.

d) As análises no domínio das freqüências são baseadas na análise de Fourier, que é conduzida no domínio das freqüências espectrais da imagem (PSM - power spectrun method). Existe uma variedade de métodos desenvolvidos para separar texturas diferentes baseados no PSM.

VESKA et al. citados por HARALICK \& SHAPIRO (1992) ao fizeram estudos comparativos para determinar qual abordagem fornecia a melhor separação de feições espaciais concluíram que as abordagens no domínio espacial - medidas estatísticas simples, e probabilidades de nível de cinza e matriz de coocorrência - fornecem uma classificação mais precisa que a análise no domínio das freqüências.

Segundo BRIGGS \& NELLIS (1991), os algoritmos texturais geram um valor que pode medir a quantidade da heterogeneidade na cobertura da terra. Tais algoritmos, geralmente medem a similaridade entre o pixel central num subconjunto da imagem e os pixels circunvizinhos na janela móvel da imagem.

Muitas feições texturais podem ser geradas de cada banda de uma imagem, usando diferentes medidas de textura, tamanhos de janelas, orientações, e valores limites de nível de cinza. No entanto, para minimizar dimensionalmente problemas com a entrada de variáveis adicionais na classificação, geralmente utiliza-se uma feição por banda.( FRANKLIN \& PEDDLE, 1990).

O tamanho das feições da superfície pode também predispor a medida da textura, pela seleção de uma dimensão apropriada para um caso particular de estudo. Por exemplo, uma janela de $3 \times 3$ pixels pode ser mais apropriada para distinguir diferentes paisagens enquanto uma janela de 10x10 é mais apropriada para a homogeneização da paisagem.

\section{MODELOS MATEMÁTICOS UTILIZADOS NA PESQUISA}

a) Algoritmo de Min-Máx: Data Range - dr

Idêntico ao algoritmo proposto por IRONS e PETERSEN, citado por JENSEN (1986), o Data Range proposto no Software ENVI (1995), é fundamentado num operador de textura min-máx, baseado na análise dos níveis de cinza da imagem, criando uma janela com elementos espaciais móveis, que foi dimensionada nesta pesquisa como 3 × 3 elementos. Este algoritmo mostra a variabilidade, ou seja, as diferenças de textura presentes em uma paisagem. 


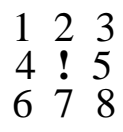

Onde:

Textura no pixel $!=$ (Intensidade de pixel mais claro em $1,2,3,4,5,6,7,8)$ (Intensidade do pixel mais escuro em 1,2,3,4,5,6,7,8)

A medida da interdependência de pixels é obtida geralmente pelo exame quantitativo da variabilidade do valor dos pixels dentro do bloco específico de pixels, e restituindo o pixel central da janela de processamento considerando a diferença entre o máximo e o mínimo valor dos pixels na janela. Na imagem com feições de textura as diferenças entre áreas são distinguidas pela diferença de brilho.

b) Matriz de Co-ocorrência Espacial

Outro algoritmo utilizado nesta pesquisa para extração de feições texturais é aquele proposto por Haralick citado em HARALICK e SHAPIRO (1992). Ele é baseado na Matriz de valor de brilho espacial dependente (algumas vezes chamada de Matriz de Co-ocorrência ou Matriz de Transição). Esta matriz mostra a quantidade de vezes que os valores de brilho ou de cinza de cada pixel ocorre em relação aos valores de cinza dos pixels vizinhos na imagem, considerando a média das quatro direções: $0^{\circ}, 45^{\circ}, 90^{\circ}, 135^{\circ}$ (vide fig. 1 ). A cada nova posição da janela (normalizada pelo índice de incremento $\mathrm{C}=(\chi, \gamma)$ ) os valores são recalculados e por fim mostrados nos elementos da matriz.

Figura 1. Oito vizinhos próximos do pixel $\mathrm{X}$, de acordo com o ângulo espacial usado para criar a matriz de co-ocorrência espacial para as medidas da textura da imagem. Fonte: Haralick em Jensen (1986)

Figure 1. Eight nearest neighbors of pixel $\mathrm{X}$ according to angle used in the creation of spatial dependency matrices for the measurement of image texture.

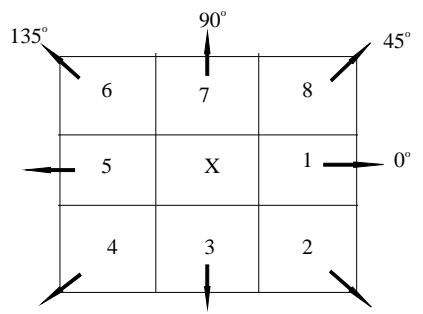

As Matrizes Espaciais de Co-ocorrência utilizadas por FRANKLIN \& PEDDLE (1990) estão ilustradas na fig. 2, a qual mostra a construção da matriz de co-ocorrência espacial direcional, para uma janela de $3 \times 3$ pixels, (como a utilizada nesta pesquisa) e um imagem normalizada para quatro níveis de cinza ( 0 a 3 ). 
Figura 2. (a) Janela de $3 \times 3$ pixels com a dimensão dos tons de cinza de 0 a 3; (b) Forma geral da matriz de co-ocorrência espacial, para a janela, \# (i,j) representam o número de vezes que os tons cinza i e j são vizinhos; ( c) Representam as matrizes de co-ocorrência espacial nas quatro direções.

Fonte: Peddle e Franklin, 1991

Figure 2. (a) $3 \times 3$ window with gray tone range $0-3$; (b) General form of the spatial cooccurrence

for window, \# $(\mathrm{i}, \mathrm{j})$ represents number of times gray tones $\mathrm{i}$ and $\mathrm{j}$ were neighbors;

(c) Represents spatial cooccurrence matrices derived for four angular orientations

\begin{tabular}{|l|l|l|}
\hline 1 & 2 & 3 \\
\hline 1 & 1 & 2 \\
\hline 0 & 1 & 2 \\
\hline
\end{tabular}

(a)

$$
\begin{array}{c|cccc} 
& 0 & 1 & 2 & 3 \\
0 & \#(0,0) & \#(0,1) & \#(0,2) & \#(0,3) \\
1 & \#(1,0) & \#(1,1) & \#(1,2) & \#(1,3) \\
2 & \#(2,0) & \#(2,1) & \#(2,2) & 3(2,3) \\
3 & \#(3,0) & \#(3,1) & \#(3,2) & \#(3,3)
\end{array}
$$

(b)

$\left|\begin{array}{llll}0 & 1 & 0 & 0 \\ 1 & 2 & 3 & 0 \\ 0 & 3 & 0 & 1 \\ 0 & 0 & 1 & 0\end{array}\right| \quad\left|\begin{array}{llll}0 & 1 & 0 & 0 \\ 1 & 4 & 1 & 0 \\ 0 & 1 & 2 & 1 \\ 0 & 0 & 1 & 0\end{array}\right| \quad\left|\begin{array}{llll}0 & 0 & 0 & 0 \\ 0 & 4 & 1 & 0 \\ 0 & 1 & 2 & 0 \\ 0 & 0 & 0 & 0\end{array}\right| \quad\left|\begin{array}{llll}0 & 1 & 0 & 0 \\ 1 & 0 & 2 & 1 \\ 0 & 2 & 0 & 0 \\ 0 & 1 & 0 & 0\end{array}\right|$

horizontal $=0^{\circ} \quad$ vertical $=90^{\circ} \quad$ diag. esq. $=135^{\circ}$ diag. direita $=45^{\circ}$ (c)

Exemplificando, se $\mathrm{C}=(\chi, \gamma)=(1,0)$, considerando a horizontal das matrizes de co-ocorrência espacial o valor 1 é adjacente ao 2 por 3 vezes na imagem, simplificando: $(1,2)=3$ (Vide ( c) da fig. 2 
c) Feições de textura:

As matrizes de co-ocorrência são computadas a partir de medidas espaciais simples representadas por texturas estatísticas, também denominadas feições de textura.

HARALICK, citado por BARBER \& LeDREW (1991), propôs utilizar estatísticas de segunda ordem para obter feições de textura, considerando para tanto as feições que são utilizadas na interpretação visual, tais como: homogeneidade, contraste, estrutura, etc. Dentre as várias medidas de textura sugeridas utilizou-se nesta pesquisa as seguintes:

a) Segundo Momento Angular (Second Moment - sm)

Mede a homogeneidade da imagem $\quad \sum_{i=1}^{n} \cdot \sum_{j=1}^{n} C_{i, j}^{2}$

b) Primeiro Momento (First Moment - fm)

$$
\sum_{i=1}^{n} \cdot \sum_{j=1}^{n} C_{i, j}^{2}(i-j)^{2}
$$

Mede o contraste da imagem

Onde: $C_{i, j}=\frac{P_{i, j}}{\sum_{i, j=1}^{n} P_{i, j}}$

$\mathrm{P}=$ freqüência de ocorrência dos níveis de cinza i e $\mathrm{j} ; \mathrm{n}=\mathrm{n}^{\mathrm{o}}$ total de par de pixels que são dependentes do parâmetro $\mathrm{C}(\chi, \gamma)$, da janela móvel $\mathrm{n}$ x m, consideradas para as quatro direções, das respectivas matrizes.

Estas feições são calculadas e atribuídas ao pixel central da janela. A medida que a janela é movida sobre a imagem se vai obtendo a banda de textura.

\section{MATERIAL E MÉTODO}

O local definido para estudo compreende a porção Norte da Ilha de São Francisco do Sul, situada no litoral de Santa Catarina, com dimensões de 847 x 715 pixels, ou seja, 25,41 km x 21,45 km (vide fig. 3). A escolha desta área foi devido a disponibilidade de imagem digital em todas as bandas e também, principalmente, pela diversidade característica de sua paisagem, o que, em hipótese, propiciaria análise mais cuidadosa das texturas estatísticas a serem usadas.

Para efeito de estudo, com auxílio do Mapa de Vegetação de Santa Catarina (IBGE, 1992) um mapa de classificação genérica da vegetação da Ilha de S. Francisco do Sul, executado pelo engo. Luiz F. F. Gonçalves, em projeto de 
consultoria à Petrobras em 1996 e UFPR (1996) definiu-se as seguintes classes de cobertura da terra:

A Manguezal; Ç Floresta Ombrófila Densa de Terras Baixas; É Floresta Ombrófila Densa

Submontana; Ñ Floresta Secundária; Ö Vegetação Herbácea de Campos Salinos ou de Ambientes Salobros; Ü Reflorestamento; á Agropecuária; à Areia, Praia; â Área Urbana; ä Água.

A classe água , apesar de não ser objeto principal de estudo, foi, no decorrer da pesquisa, subdividida em 4 classes devido a presença de sedimentos no canal da baía da Babitonga.

A imagem utilizada é de 1990, do Sensor LANDSAT-5 TM.

Figura 3: Localização Geográfica da Área de Estudo

Figure 3: Geographic Localization of Study Area

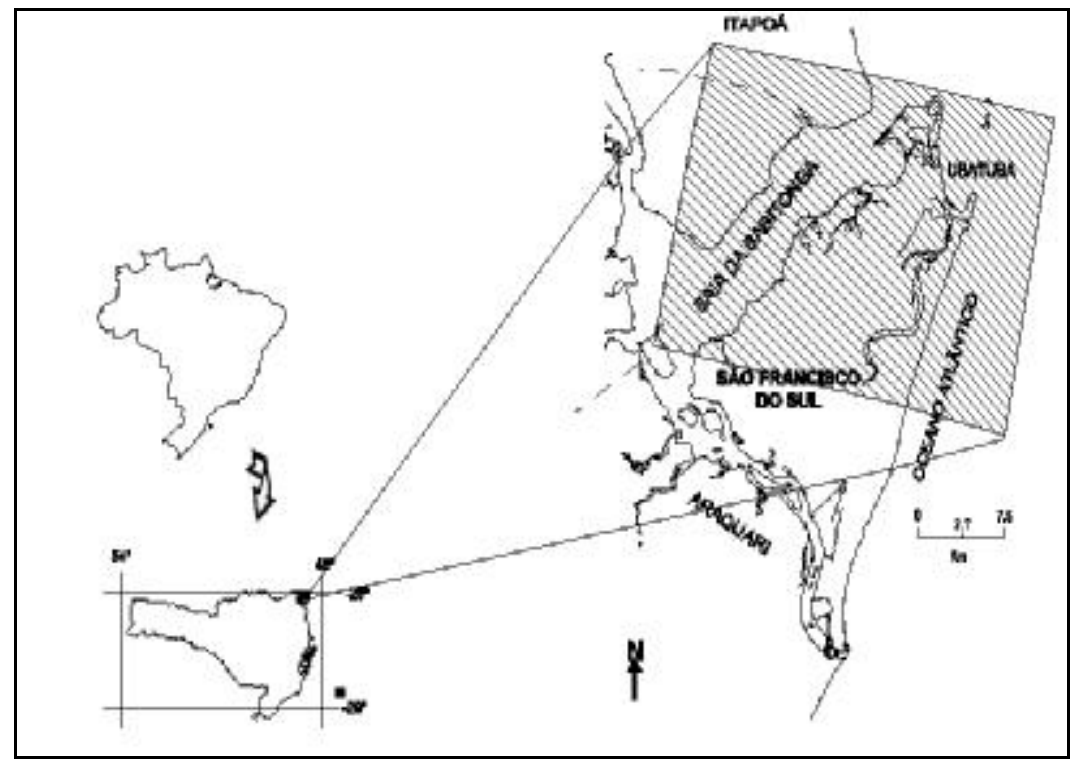




\section{PROCESSAMENTO E CLASSIFICAÇÃO DA IMAGEM}

O algoritmo definido para a classificação da imagem foi o Maxver Máxima verossimilhança, que se insere no grupo de processos estatísticos de classificação supervisionada.

Considerando as seis bandas óticas disponíveis, após uma análise visual da imagem na tela do vídeo, foi selecionado o triplete de bandas 4, 5, 3, em R G B respectivamente, para as classificações porque este triplete mostrou boa qualidade visual. A Classificação da imagem foi efetuada de quatro maneiras:

a) Classificação Espectral das três bandas.

b) Classificação Espectral de duas bandas mais a textura na banda 3 .

c) Classificação dos três canais de componentes principais originados das bandas 4,5,3 e três bandas texturais obtidas da banda 3 .

d) Classificação dos três canais de componentes principais originados das bandas 4,5,3 e três bandas texturais obtidas da banda 5 .

\section{a) Classificação Espectral}

A classificação espectral foi conduzida distintamente na maneira de definir as amostras de cada classe, onde se teve como saída duas imagens de classes de Cobertura da Terra.

Para a primeira classificação foram definidas as amostras de cada classe a partir do conhecimento da área e do mapa da cobertura vegetal. O resultado da classificação está na fig. 4.

Para conhecer a capacidade do software utilizado, optou-se por executar mais uma classificação onde se definiu as amostras de cada classe com o auxílio de "Regiões de Interesse - ROIs ". As ROIs são obtidas pela escolha e delineamento na imagem, de áreas de interesse para a classificação, para a seguir redefiní-las (à que classe pertencem), utilizando diagrama de dispersão (n- dimensional visualiser). O resultado desta classificação pode ser observado na figura 5. A água foi nesta classificacação subdividida em cinco classes utilizando ROIs.

b) Classificação Espectral de duas bandas e a textura na banda 3

A imagem foi processada três vezes para se obter os canais de textura. $\mathrm{O}$ primeiro processamento foi com a banda 4 , resultando três canais de textura, dr4, fm4, sm4. O segundo com a banda 5, resultando mais três canais de textura, dr5, fm5, sm4, e finalmente com a banda 3, resultando outros três canais de textura, dr3, fm3, dr3. Obteve-se, assim, nove canais de textura e três bandas espectrais

Um estudo visual exaustivo (observando a imagem na tela do vídeo) foi realizado para determinar os tripletes de bandas com melhor qualidade visual, para a classificação da imagem, onde, optou-se por dois tripletes : bandas $4,5, \mathrm{dr} 3 ; \mathrm{e} 4$, 5,sm3 (leia-se: dr3 = data range na banda 3; e sm3 = second moment na banda 3, que são as bandas texturais)

Foram consideradas as mesmas classes definidas para a classificação (a), no entanto, devido a banda de textura, algumas amostras de treinamento precisaram ser redefinidas. O resultado da classificação do triplete 4, 5, sm3 está na figura 6. 
c) Classificação dos três canais de componentes principais originados das bandas 4, 5, 3 e três bandas texturais obtidas da banda 3 .

Embasado na metodologia desenvolvida por COGO (1993) definiu-se um triplete de bandas com as três primeiras componentes principais originados das três bandas espectrais e três canais texturais da banda 3 ( 4, 5, 3, dr3, fm3, e sm3), para compor a imagem a ser classificada. $\mathrm{O}$ resultado da classificação está mostrado na figura 7 .

d) Classificação dos três canais de componentes principais originados das bandas 4, 5, 3 e três bandas texturais obtidas da banda 5 .

Para comparar resultados, e seguindo a metodologia de COGO (1993), um novo triplete com as três primeiras componentes principais foi originado das três bandas espectrais e três canais texturais da banda $5(4,5,3, \mathrm{dr} 5$, fm5, e sm5). $\mathrm{O}$ resultado da classificação desta imagem está mostrado na figura 8 . 


\section{RESULTADOS E DISCUSSÕES}

$\mathrm{Na}$ análise visual dos mapas originados das classificações efetuadas observou-se o seguinte:

Classificação (a): Figura 4

Classes da Cobertura da Terra em São Francisco do Sul

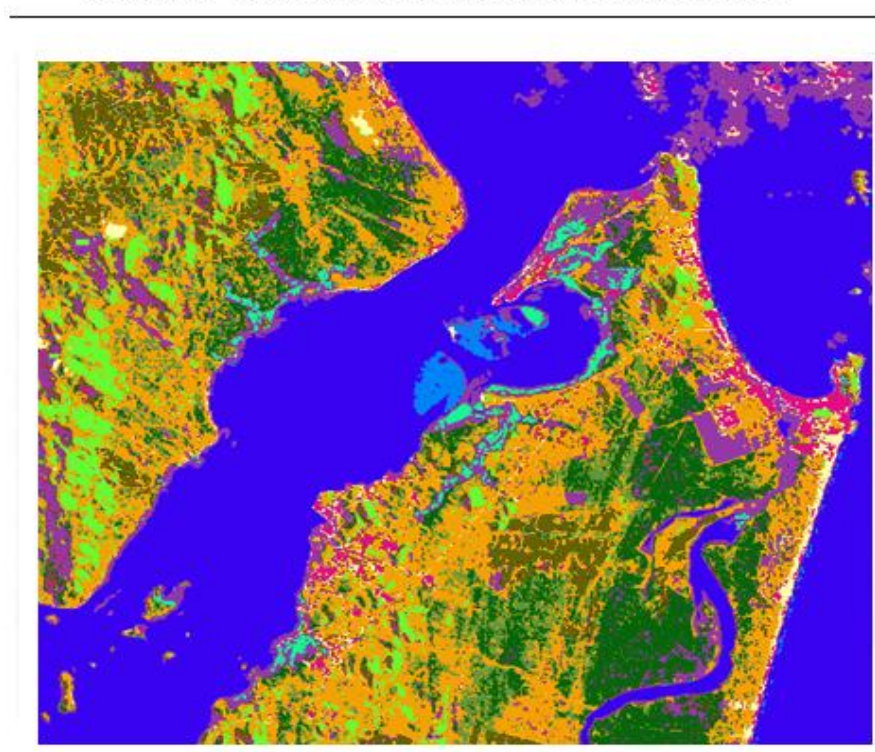

\begin{tabular}{|c|c|}
\hline 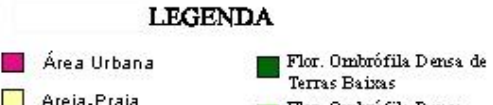 & $\begin{array}{l}\text { Escala } \\
1 \quad 0 \quad 1 \\
\end{array}$ \\
\hline $\begin{array}{l}\square \text { Agropecuária } \\
\square \text { Submontaná } \\
\text { Veg. Herb. de Amb.Salinos } \square \text { Água Mar e Rio } \\
\text { eiou ambientes salobros } \square \text { Sedim. } 1 \text { em Suspensão } \\
\square \text { R eflores tamento }\end{array}$ & $\mathbf{N}$ \\
\hline $\begin{array}{l}\square \text { Manguesal } \\
\square \text { Floresta Secundária }\end{array}$ & $\begin{array}{l}\text { Im agem Lands at 5TM } \\
\text { Data: } 1990 \\
\text { Bamdas: } 3,4,5\end{array}$ \\
\hline
\end{tabular}

FIGURE 4: Classificação Espectral

FIGURE 4: Spectral Classification

As sombras do relevo e as nuvens foram confundidas com área de Ambientes Salobros e Vegetação Herbácea.

A área de Uso Agropecuário foi confundida com a classe Floresta Secundária e Floresta Densa de Terras Baixas e Submontana. 
Classificação (a): Figura 5

\section{Classes da Cobertura da Terra em São Francisco do Sul}

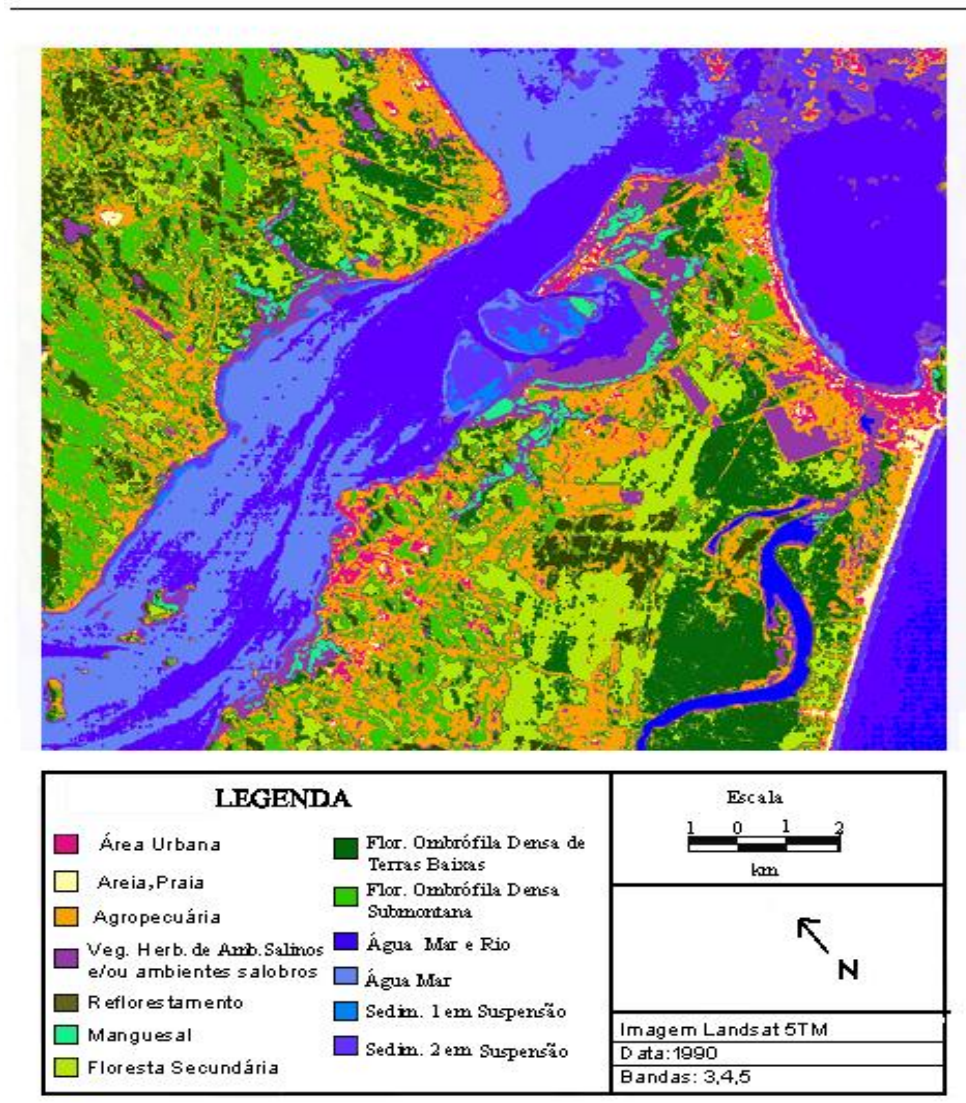

FIGURA 5: C1assificação E spectral utilizando ROIS

FIGURE 5: Spectral Classific ation using ROIS

A classificação espectral efetuada com auxílio de "Regiões de Interesse ROIs para a definição das amostras de cada classe, mostrou que esta ferramenta é mais eficiente quando se escolhe ROIs em classes bem distintas, como por exemplo água e areia, ou vegetação e água. Na análise visual do resultado desta classificação, verificou-se que as sombras do relevo continuam sendo confundidas com outra classe, desta vez com Reflorestamento, mas as florestas foram melhor discriminadas. Nesta classificação foram incluídas cinco classes d'água, que passaram a ser consideradas doravante na classificação usando feições texturais. 
Classificação (b) - Bandas 4, 5, sm3: Figura 6

Classes da Cobertura da Terra em São Francisco do Sul
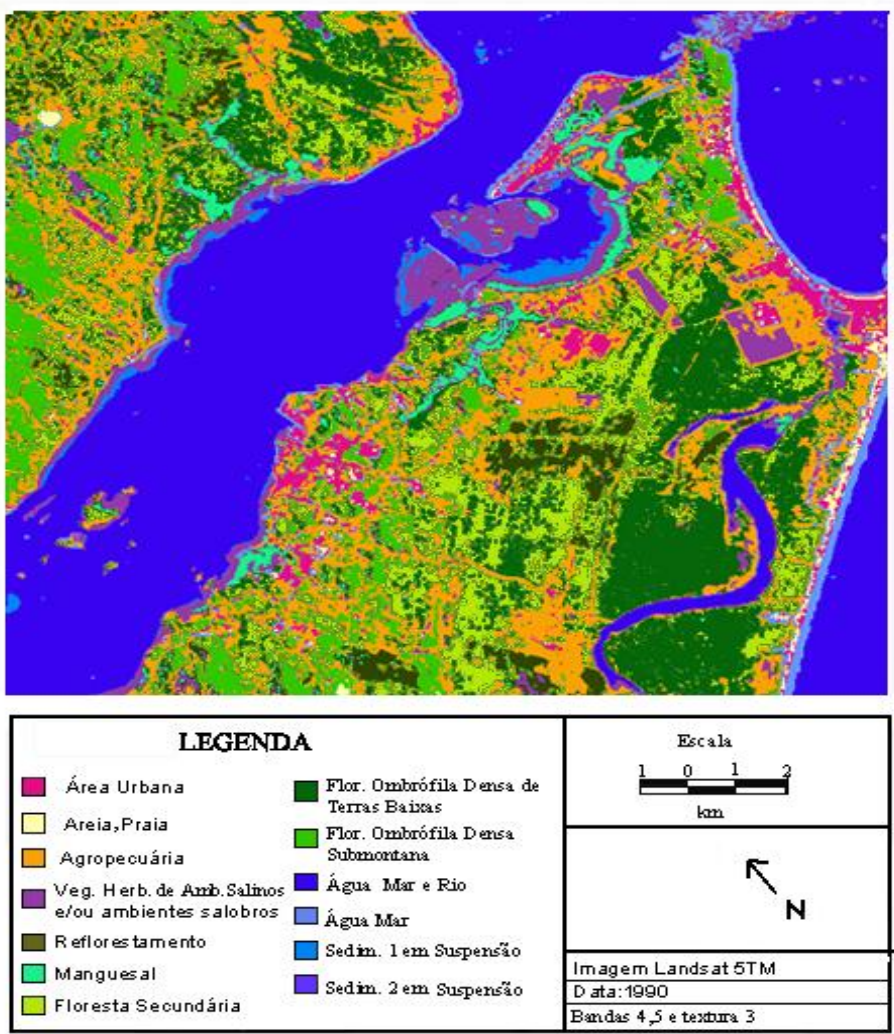

FIGURA 6: Classificação Espectral usando bandas 4,5 e tex tura na banda 3 . FIGURE 6: Spectral Classific ation using 4,5 band and texture of channe1 3.

A aplicação do algoritmo segundo momento angular na banda 3 (sm3) para gerar o triplete de bandas utilizadas na classificação da imagem, colocou a área Urbana em evidência, fato que não ocorreu anteriormente. As classes Manguezal e Ambientes Salobros ou Campos Salinos também parecem ocupar maior área na orla do oceano, que aquela da classificação anterior. Isto sugere que o algoritmo textural cumpriu sua função em separar classes hogêneas.

As sombras do relevo deixaram de ser confundidas com a classe Reflorestamento, como ocorreu na primeira classificação, mas este por sua vez ocupa menor área que na classificação (a). 
Classificação (c) - Componentes principais com texturas na banda 3: Figura 7

Classes da Cobertura da Terra em São Francisco do Sul


FIG URA 7: Classific ação das três componentes principais originadas das bandas 4,5,3 mais três canais de textur a da banda 3 .

FIG URE 7: This classificacion $w$ as made bv 3 principals components from band 4,5,3 plus three channels of texture from band 3 .

Comparando com as outras classificações observa-se que os Manguezais aumentaram em área, sugerindo melhoria na sua discriminação. O mesmo ocorreu com a classe Vegetação Herbácea de Campos Salinos e Ambientes Salobros.

Com relação à área urbana, observa-se nitidamente na imagem, o delineamento das ruas e inclusive, das estradas municipais existentes na área em análise, que não apareciam nas outras classificações.

As áreas de influência antrópica, como na classe de Atividade Agropecuária, foi bem discriminada nesta classificação, enquanto que ao se usar só a classificação espectral isto não ocorreu. Também para as classes de florestas houve melhora significativa na discriminação das classes, com exceção para o Reflorestamento que não foi possível distinguir de Floresta Densa de Terras Baixas. 
As áreas de sombra provenientes da ondulação do relevo foram confundidas com Manguezal e Floresta Densa de Terras Baixas.

Estes fatos levam à consideração de que os canais texturais melhoraram a classificação da imagem quando características texturais definidas pela densidade e tonalidade eram bastante diferentes, denotando textura lisa, textura média, e textura rugosa. Fato este evidenciado ao se considerar as classes de vegetação; quando estas apresentavam fisionomia do dossel semelhantes (textura semelhante) os canais texturais utilizados não conseguiram separar as classes.

Classificação (d) - Componentes principais com texturas na banda 4: Figura 8

\section{Classes da Cobertura da Terra em São Francisco do Sul}
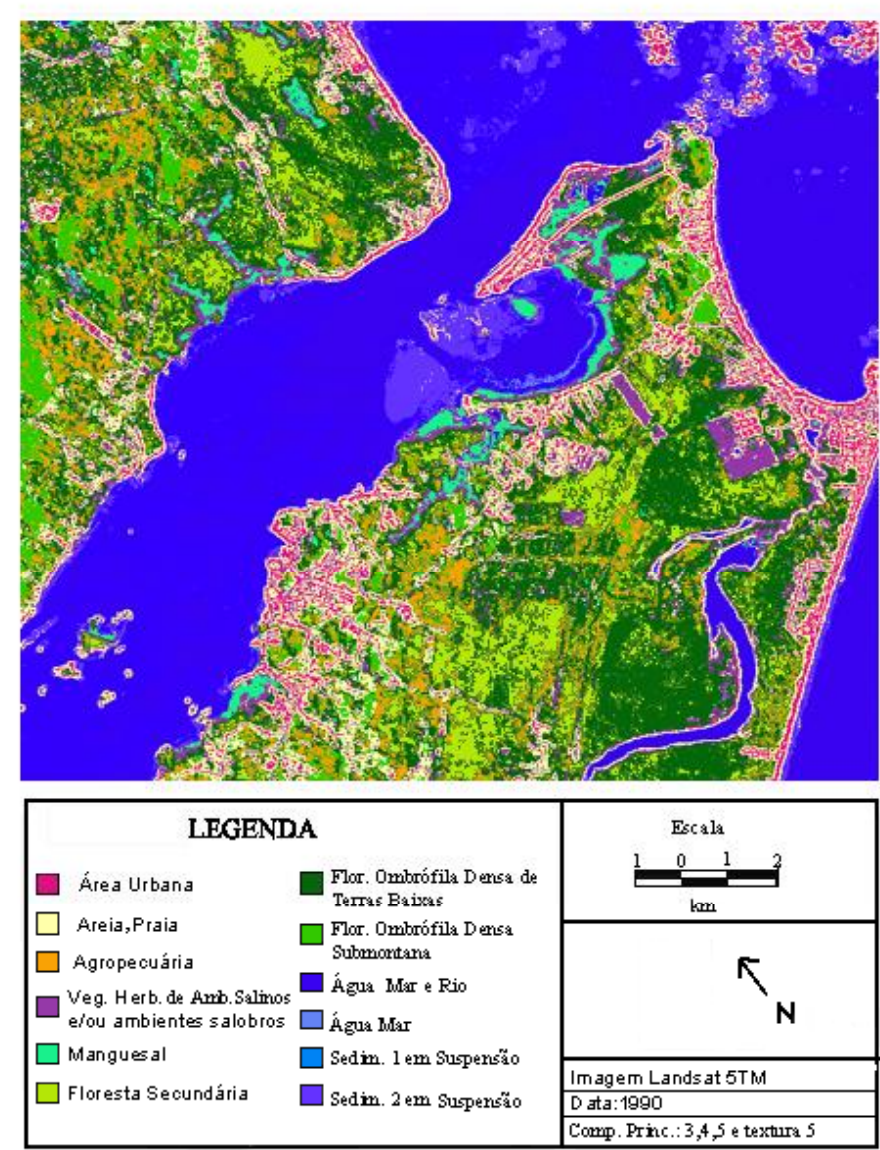

FIGURA 8:Classificação das três componentes principais originadas das bandas $4,5,3$ mais três cancis de textura da banda 5 .

FIGURE 8:Thisclassification $w$ as made bv thr eeprincipals components from band $4,5,3$ plus three channels of texture from band 3 . 
Esta classificação não apresentou bons resultados. Comparando visualmente a imagem gerada pela composição das componentes principais e texturas na banda 5 , com aquela gerada para a classificação (c), percebeu-se que a primeira não apresentava a mesma qualidade visual que a última. A banda textural provocou um efeito de borda nos limites das classes de Água e Área Urbana. Observando-se os mapas da classificação (c ) na fig. 7 e da classificação (d) na figura 8, observa-se que neste último as classes Área Urbana e Areia aumntaram, ocupando a'reas que na figura 7 eram de uso agropecuário, estas por sua vez apareceram confundidas com as classes de Florestas.

\section{CONCLUSÕES}

Considerando as quatro formas de classificação, elegeu-se a classificação (c ) como a que apresentou melhores resultados na discriminação das classes de cobertura da terra.

Comparando visualmente os mapas temáticos das figuras 4 e 7 , resultantes das classificações (a ) somente análise multiespectral e da (c ) classificação multiespectral considerando uma banda textural, respectivamente, é fácil perceber que esta última discriminou melhor as classes de interesse. No entanto, permaneceram algumas confusões, como classes de Manguezal, Reflorestamento e Floresta Densa de Terras Baixas.

Acredita-se que os padrões texturais, muito semelhantes, destas classes (devido ao contexto em que estão inseridas), não possibilitaram uma boa discriminação em alguns locais da área em consideração.

Os algoritmos de medida de textura utilizados: segundo momento angular para a medida da homogeneidade, primeiro momento angular para a medida de contraste e data range para a medida dos valores de cinza, foram mais eficientes na separação das classes de cobertura da terra quando a textura das classes eram bem diferenciadas. Exemplos disto são as classes de floresta: devido do tipo e ao arranjo espacial dos elementos, ora mais densos ora menos densos, altura da copa e a aparência do dossel dos diferentes tipos de cobertura vegetal, mostravam padrões de densidade distintos indo desde textura lisa até a rugosa. Onde as diferenças texturais não eram significativas (já explicado acima) as classes não foram bem discriminadas. Outro exemplo do bom desempenho dos algoritmos texturais utilizados foi na melhora da discriminação da classe Área Urbana. Observa-se nitidamente na imagem, o delineamento das ruas e inclusive, das estradas municipais existentes na área em análise, que não apareciam nas outras classificações.

Os resultados obtidos nestas classificações podem ser mais explorados considerando tamanhos diferenciados de "janelas" para a construção das matrizes espectrais de co-ocorrência, pois nesta pesquisa dimensionou-se uma janela de $3 \times 3$ pixels. A escolha deste tamanho foi embasado na literatura, que aponta o uso de janelas pequenas para as áreas mais heterogêneas, como é o caso da área em estudo. 
No entanto, deve-se ter em mente que apesar das melhorias na classificação de imagens multiespectrais, dificuldades na delimitação de algumas tipificações devem continuar a ocorrer devido às limitações temporais, espectrais e espaciais da imagem de satélite.

Por outro lado, considera-se que os objetivos desta pesquisa: (a ) iniciar estudos para aplicações de feições texturais em imagens de satélite, (b) confrontar resultados da classificação espectral de imagens multiespectrais do LANDSAT-5 TM, com aqueles da classificação espectral associada à feições de textura, para a discriminação de classes de cobertura da terra, com ênfase na separação das classes de cobertura vegetal, foram plenamente atingidos.

\section{BIBLIOGRAFIA CITADA}

BARBER, D. G. \& LeDREW E. F. 1991. Sar sea ice using texture statistics: a multivarate approach. Photogrammetric Engeneering \& Remote Sensing. . V. 57, n. 4, p. 385-395, abr.

BRIGGS , J. M. 1991. Seasonal variation of heterogeity in the tallgrass prairie: a quantitative measure using remote sensing. Photogrammeetric Engeneering \& Remote Sensing. V. 57, n. 4, p. 407-411, abr.

COGO , S. E. V. Feições de textura para classificação de imagens. In: VII SIMPÓSIO BRASILEIRO DE SENSORIAMENTO REMOTO (1993 : Curitiba). Anais... São José dos Campos : INPE, Gráfica, 1993. p. 339-346

CRÓSTA, A. P. 1992. Processamento digital de imagens de sensoriamento remoto Campinas : IG/UNICAMP.

FRANKLIN, S. E. PEDDLE, D. R. 1990. Classification of SPOT HRV imagery and texture features . International Journal Remote Sensing. V. 11, n. 3, p. 551-556, 1990. Photogrammetric Engeneering \& Remote Sensing. V. 56, n. 02, p. 211-224, fev.

1987. Texture analises of digital image data using spatial cooccurrence.

Computers \& Geosciences. V. 13, n. 03, p. 293-311.

IBGE - Instituto Brasileiro de Geografia e Estatística. Manual técnico da vegetação brasileira. Manuais técnicos em geociências, 1. Rio de Janeiro, IBGE, 1992.

HARALICK, R. M. \& SHAPIRO L. G. 1992. Texture. In: Computer and robot vision v. 1. New York, USA : Addison-Wesley Publishing Company. p. 453-494. 
JENSEN, J. R. 1986. Introductory digital image processing. New Gersey : Prentice Hall.

PEDDLE, D.R. e FRANKLIN, S. E. 1991. Image Texture processing and data integration for surface pattern discrimimation. Photogrammetric Engeneering \& Remote Sensing. V. 57, n. 4, p. 413-420, abr.

MANUAL do ENVI ${ }^{\mathrm{TM}}$, version 2.0. 1995. Boulder, Colorado/USA: Research Systems.

SCHWENGERT, R. A. 1983. Techniques for image processing and classificatio in remote sensing. Orlando, Florida: Academic Press.

TREITZ, P. M. \& BARBER, D. G. \& HOWARTH, P. J. s.d. Texture measures for discrimination of agricultiral crops in Southwestern Ontario. In: XIV CANADIAN SYMPOSIUM ON REMOTE SENSING. (cópia Anais s.l., s.d.)

UFPR - UNIVERSIDADE FEDERAL DO PARANÁ. Setor de Ciências Agrárias, Departemento de Silvicultura e Manejo (1996). Levantamento da vegetação da área de proteção ambiental de Guaratuba -APA de Guaratuba Curitiba.

VISA, A. 1990. Texture classification and segmentation based on neural network methods. Espoo, Finland. Tese (Doutorado em Tecnologia) Helsinki University of Tecnology. 